Tropical Journal of Pharmaceutical Research June 2020; 19 (6): 1161-1166

ISSN: $1596-5996$ (print); 1596-9827 (electronic)

(C) Pharmacotherapy Group, Faculty of Pharmacy, University of Benin, Benin City, 300001 Nigeria.

\title{
Trigonoside II mitigates sepsis-induced myocardial injury via reduction in oxidative stress and regulation of TLR- 4/NF-kB inflammatory pathway
}

\author{
Fengru Wang ${ }^{1}$, Lili Wu², Qun Liang ${ }^{2 *}$ \\ ${ }^{1}$ Department of Cardiovascular Medicine, The First Affiliated Hospital of Heilongjiang University of Chinese Medicine, \\ ${ }^{2}$ Heilongjiang University of Chinese Medicine, ${ }^{3}$ Department of Critical Care Medicine, The First Affiliated Hospital of \\ Heilongjiang University of Chinese Medicine, Harbin, Heilongjiang 150040, China
}

*For correspondence: Email: liangqun1@sina.com; Tel: 0086-0451-82111401

Sent for review: 27 September 2019

Revised accepted: 22 May 2020

\begin{abstract}
Purpose: To investigate the protective effect of trigonoside II against sepsis-induced myocardial injury in rats, and the mechanism involved.

Methods: Adult male Sprague Dawley rats $(n=30)$ weighing $200-230 \mathrm{~g}$ (mean weight $=215 \pm 15 \mathrm{~g}$ ) were used for this study. The rats were randomly assigned to 3 groups (10 rats/group): sham, cecal ligation puncture (CLP), and trigonoside II. Rats in the treatment group received trigonoside II at a dose of $2 \mathrm{mg} / \mathrm{kg}$ intraperitoneally (i.p.) at 3, 12 and $24 \mathrm{~h}$ post-surgery. Sepsis was induced using CLP method. Lactate dehydrogenase (LDH) and creatine kinase (CK-MB) activities, and hemodynamic functions were determined in the rats. The levels of interleukin (IL)-1 $\beta$ and IL-6, and tumor necrosis factor $\alpha(T N F-\alpha)$ were assayed in rat serum. Oxidative stress and myocardial cell apoptosis were determined by measuring malondialdehyde (MDA) levels, while activities of glutathione peroxidase $(G P x)$, superoxide dismutase (SOD) and myeloperoxidase (MPO), as well as levels of expression of bax, bcl-2 and caspase-3 were also assessed.

Results: Treatment of myocardial injury rats with trigonoside II led to significant reductions in the activities of $L D H, C K-M B$ and MPO, and decreases in levels of IL-1 $\beta, I L-6$ and TNF- $\alpha(p<0.05)$. It also significantly reversed the effects of sepsis on rat hemodynamic functions $(p<0.05)$. Trigonoside II treatment significantly reduced MDA levels in rat myocardial tissues, but significantly increased SOD and GPx activities $(p<0.05)$. It significantly down-regulated protein expressions of NF-kB and TLR-4 in myocardial tissues $(p<0.05)$. The number of apoptotic cells and activity of caspase-3 were significant increased in myocardial tissues of rats in CLP group, when compared with sham group, but were reduced significantly in myocardial tissues of trigonoside II-treated rats $(p<0.05)$. Similarly, trigonoside II treatment down-regulated the protein expressions of caspase-3 and bax, but upregulated bcl-2 protein expression in the rat myocardial tissues $(p<0.05)$.

Conclusion: The results of this study indicate that trigonoside II confers protection on sepsis-induced myocardial injury via reduction in oxidative stress and regulation of TLR-4/NF-kB inflammatory pathway.
\end{abstract}

Keywords: Cecal ligation puncture, Myocardial injury, Oxidative stress, Sepsis, Trigonoside II

This is an Open Access article that uses a fund-ing model which does not charge readers or their institutions for access and distributed under the terms of the Creative Commons Attribution License (http://creativecommons.org/licenses/by/4.0) and the Budapest Open Access Initiative (http://www.budapestopenaccessinitiative.org/read), which permit unrestricted use, distribution, and reproduction in any medium, provided the original work is properly credited.

Tropical Journal of Pharmaceutical Research is indexed by Science Citation Index (SciSearch), Scopus, International Pharmaceutical Abstract, Chemical Abstracts, Embase, Index Copernicus, EBSCO, African Index Medicus, JournalSeek, Journal Citation Reports/Science Edition, Directory of Open Access Journals (DOAJ), African Journal Online, Bioline International, Open-J-Gate and Pharmacy Abstracts 


\section{INTRODUCTION}

Sepsis occurs when chemicals released in the bloodstream to fight an infection trigger inflammation. This causes a cascade of changes that damage multiple organ systems, making them to fail, sometimes even resulting in death [1]. The resultant multiple organ dysfunction is due to the release of inflammatory cytokines [2]. The symptoms include fever, difficulty breathing, low blood pressure, fast heart beat and mental confusion. Sepsis is usually treated with antibiotics and intravenous fluids.

Apoptosis, reactive oxygen species (ROS) and oxidative stress have been implicated in sepsisinduced myocardial injury [3,4]. Heme oxygenase-1 (HO-1), a heat-stable protein that regulates oxidative stress, has been shown to reduce myocardial injury [5]. It activates Nrf-2, a basic leucine zipper (bZIP) protein that regulates the expression of antioxidant proteins which protect tissues against oxidative damage triggered by injury and inflammation. Studies have shown that the regulation of $\mathrm{Nrf}-2 / \mathrm{HO}-1$ pathway protects myocardial tissues from arrhythmia in acute myocardial ischemia/reperfusion (I/R) injury [6]. The strategies currently deployed for the treatment of sepsis are ineffective, hence the search for novel compounds with promising therapeutic potential for the disease. Astragali radix, a herb used in Traditional Chinese Medicine (TCM) possesses antiviral, antitumor, antidiabetic, hepatoprotective, cardiotonic and immunomodulatory effects [7]. Trigonoside II, a cycloartane triterpene glycoside isolated from Astragali radix, is reported to possess antibacterial and anticancer properties [8,9]. The aim of this study was to investigate the protective effect of trigonoside II against sepsis-induced myocardial injury in rats, and the mechanism involved.

\section{EXPERIMENTAL}

\section{Animals}

Adult male Sprague Dawley rats $(\mathrm{n}=30)$ weighing $200-230 \mathrm{~g}$ (mean weight $=215 \pm 15 \mathrm{~g}$ ) were used for this study. They were housed in metal cages under standard conditions, and were allowed free access to standard feed and water. The rats were exposed to 12-h light/12-h dark cycle and maintained at a temperature $25^{\circ} \mathrm{C}$ and $60 \%$ humidity. The study protocol was approved by the Institutional Animal Ethical Committee of Heilongjiang University of Chinese Medicine, China (approval no. IACE/HU-CM/2017/16), and carried out according to the guidelines of Association for the Assessment and
Accreditation of Laboratory Animal Care International (AAALAC) [10].

\section{Study design}

Sepsis was induced using CLP method as previously reported. The rats were anesthetized via intraperitoneal injection of chloral hydrate at a dose of $350 \mathrm{mg} / \mathrm{kg}$ bwt, and their ceca were exposed by making a $2-3 \mathrm{~cm}$ incision on their abdominal midlines. The midpiece of each cecum was ligated using 4-0 silk. The point of ligation was perforated twice with 18-gauge needle, and the potency of puncture was assessed by allowing stool to spill through the incisions. The rat abdomen was thereafter closed using suture after placing the cecum into the intra-abdominal position. The rats were then randomly assigned to three groups of ten rats each: sham group, CLP group and trigonoside II group. Rats in the treatment group received trigonoside II at a dose of $2 \mathrm{mg} / \mathrm{kg}$ bwt i.p. at 3 , 12 and $24 \mathrm{~h}$ post-surgery.

\section{Assay of activities of LDH and CK-MB}

Venous blood was drawn from each rat and centrifuged at $3500 \mathrm{rpm}$ for $30 \mathrm{~min}$ to obtain serum. The activities of LDH and CK-MB were determined in the serum using their respective assay kits.

\section{Determination of hemodynamic functions}

The hemodynamic parameters i.e. maximum increase/decrease in left ventricular pressure $\left( \pm \mathrm{dP} / \mathrm{dt}_{\max }\right)$, left ventricular end diastolic pressure (LVEDP), left ventricular systolic pressure (LVSP) and heart rate were determined in each rat by inserting a pressure transducer and catheter into the left ventricle from right carotid artery.

\section{Determination of expression levels of inflammatory cytokines}

The levels of IL-1 $\beta$, IL-6 and TNF- $\alpha$ were determined in sera of $\mathrm{I} / \mathrm{R}$ injured rats using their respective enzyme-linked immunosorbent assay (ELISA) kits.

\section{Assessment of apoptosis}

Cardiac cell apoptosis was determined using terminal deoxynucleotidyl transferase dUTP nick end labeling (TUNEL) assay. The TUNELpositive cells were identified under a trinuclear microscope using Apop Tag plus peroxidase in situ apoptosis detection kit. 


\section{Assay of caspase-3 activity}

The activity of caspase- 3 was determined using Caspase-Glo® 3 assay kits (Promega, USA) system.as per manufacturer's instructions.

\section{Evaluation of MPO activity}

The activity of MPO was assayed using MPO assay kits in line with the manufacturer's instructions.

\section{Determination of levels of oxidative stress markers}

The level of MDA, and activities of GPx and SOD were determined using their respective ELISA kits as per manufacturer's instructions.

\section{Western blotting}

Myocardial tissues were trypsinized with $10 \%$ trypsin and the resultant cell suspension was washed twice with phosphate-buffered saline (PBS) and lysed with $250 \mu \mathrm{L}$ of ice-cold radioimmunoprecipitation assay (RIPA) buffer containing protease and phosphatase inhibitors. The resultant lysate was centrifuged at 14,000 rpm for $20 \mathrm{~min}$ at $4{ }^{\circ} \mathrm{C}$, and the protein concentration of the supernatant was determined using BCA method. A portion of total cell protein $(10 \mu \mathrm{g})$ from each sample was separated on 10 $\%$ sodium dodecyl sulphate (SDS)polyacrylamide gel electrophoresis and transferred to a fixed polyvinylidene fluoride membrane at $110 \mathrm{~V}$ and $90{ }^{\circ} \mathrm{C}$ for $120 \mathrm{~min}$. Subsequently, non-fat milk powder (5\%) in Trisbuffered saline containing $0.2 \%$ Tween-20 (TBST) was added with gentle shaking at $37^{\circ} \mathrm{C}$ and incubated to block non-specific binding of the blot. Incubation of the blots was performed overnight at $4{ }^{\circ} \mathrm{C}$ with rabbit primary polyclonal antibodies against TLR-4, NF-kB, bax, bcl-2, caspase- 3 , and $\beta$ actin, each at a dilution of 1 to 1000. Then, the membrane was washed thrice with PBS and further incubated with horseradish peroxidase-conjugated goat anti-rabbit IgG secondary antibody for $1 \mathrm{~h}$ at room temperature. The blot was developed using an X-ray film. Grayscale analysis of the bands was performed using enhanced chemiluminescence (ECL). The respective protein expression levels were normalized to that of $\beta$-actin which was used as a standard.

\section{Statistical analysis}

Data are expressed as mean \pm SEM. Statistical analysis was performed using GraphPad Prism (6.1). Groups were compared using Dunnett's post hoc test. Statistical significance was assumed at $p<0.05$.

\section{RESULTS}

\section{Effect of trigonoside II on the activities of myocardial LDH and CK-MB}

Treatment of myocardial injury rats with trigonoside II led to significant reductions in the activities of LDH and CK-MB ( $p<0.05$; Figure 1$)$.

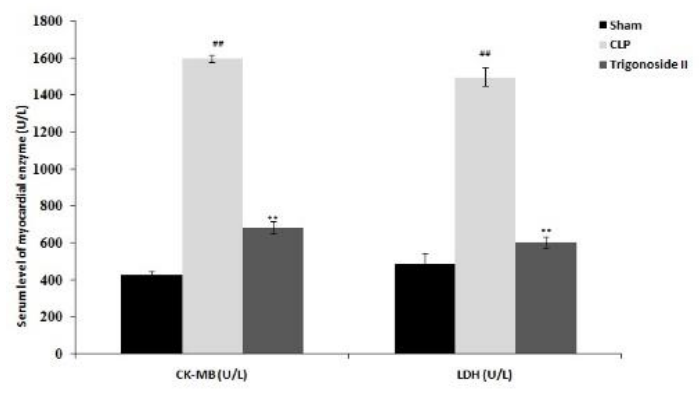

Figure 1: Effect of trigonoside II on activities of myocardial LDFH and CK-MB; \# $p<0.05$, compared with sham group; ${ }^{\star *} p<0.05$, compared with CLP group

\section{Effect of trigonoside II on hemodynamic functions}

As shown in Figure 2, LVEDP was significantly increased, while LVSP, LV+dP/dtmax and LV$\mathrm{dP} / \mathrm{dt}_{\max }$ decreased significantly in CLP group, relative to sham group $(p<0.05)$. However, trigonoside II treatment significantly reversed the effects of sepsis on the rat hemodynamic functions $(p<0.05)$.
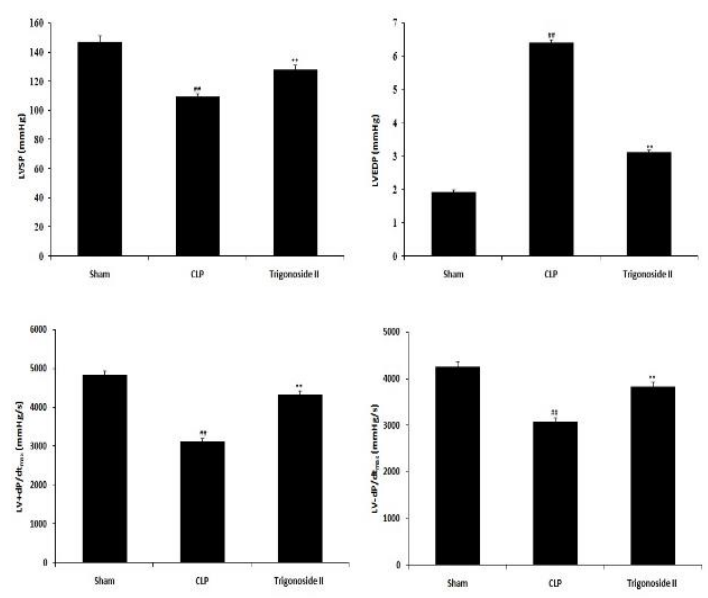

Figure 2: Effect of trigonoside II on rat hemodynamic functions; ${ }^{\#} p<0.05$, compared with sham group; ${ }^{* *} p$ $<0.05$, compared with CLP group 
Effect of trigonoside II on the levels of inflammatory cytokines

Trigonoside II treatment significantly reduced the levels of IL- $1 \beta, \mathrm{IL}-6$ and TNF- $\alpha$ in myocardial injury rats $(p<0.05)$. These results are shown in Figure 3.

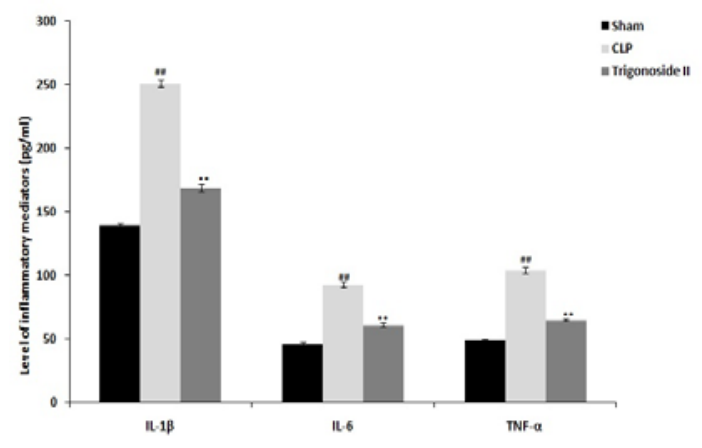

Figure 3: Effect of trigonoside II on serum levels of inflammatory cytokines; \# $p<0.05$, when compared with sham group; ${ }^{* *} p<0.05$, when compared with CLP group

\section{Effect of trigonoside on activity of MPO in myocardial injury rats}

As shown in Figure 4, the activity of MPO was significantly increased in myocardial tissues of rats in CLP group, when compared with sham group, but was significantly reduced in myocardial tissues of trigonoside II-treated rats $(p<0.05)$.

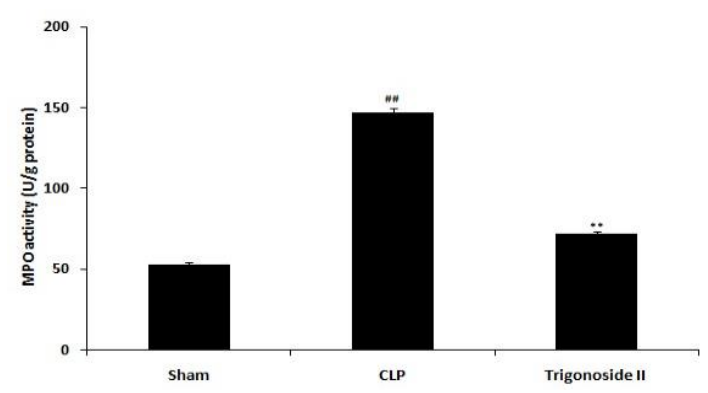

Figure 4: Effect of trigonoside II on the level of inflammation in myocardial tissues of rats; \# $p<0.05$, when compared with sham group; ${ }^{* *} p<0.05$, when compared with CLP group

\section{Effect of trigonoside II on oxidative status of myocardial injury rats}

As shown in Figure 5, treatment of myocardial injury rats with trigonoside II significantly reduced the level of MDA in their myocardial tissues, but significantly increased the activities of SOD and GPx $(p<0.05)$.
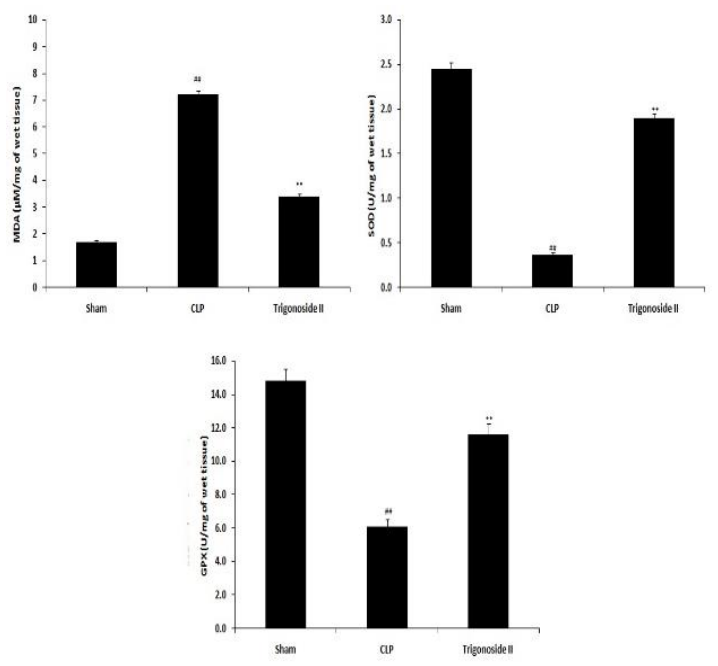

Figure 5: Effect of trigonoside II on markers of oxidative stress in myocardial tissues of rats; ${ }^{\#} p<$ 0.05 , compared with sham group; ${ }^{* *} p<0.05$, compared with CLP group

\section{Effect of trigonoside II on protein expression levels of TLR-4 and NF-kB}

Trigonoside II treatment significantly downregulated the protein expressions of NF-kB and TLR-4 in myocardial tissues of myocardial injury rats $(p<0.05)$. These results are shown in Figure 6.

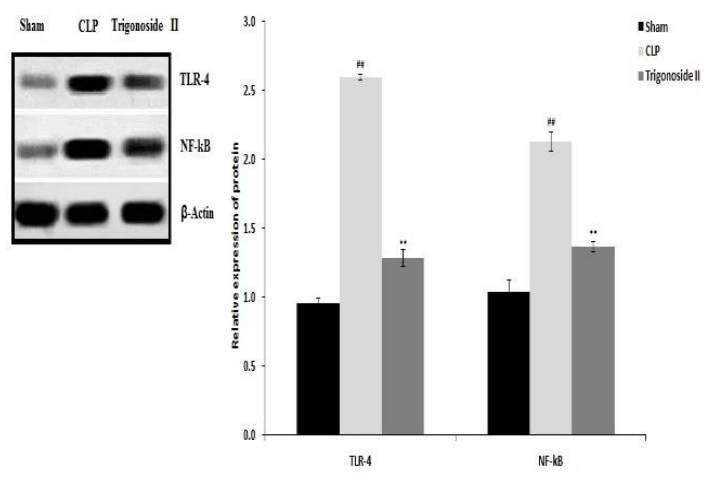

Figure 6: Effect of trigonoside II on protein expressions of TLR-4 and NF-kB in myocardial tissues of rats; ${ }^{\# \#} p<0.05$, compared with sham group; ${ }^{* *} p<$ 0.05, compared with CLP group

Effect of trigonoside II on expression levels of markers of apoptosis in myocardial tissues of rats

The number of apoptotic cells and activity of caspase-3 were significantly increased in myocardial tissues of rats in CLP group, when compared with sham group, but were reduced significantly in myocardial tissues of trigonoside II-treated rats $(p<0.05$; Figures $7 \mathrm{~A}$ and $7 \mathrm{~B})$. 
Similarly, trigonoside II treatment significantly down-regulated the protein expressions of caspase- 3 and bax, but significantly upregulated bcl-2 protein expression in myocardial tissues of myocardial injury rats $(p<0.05$; Figure $7 C)$.
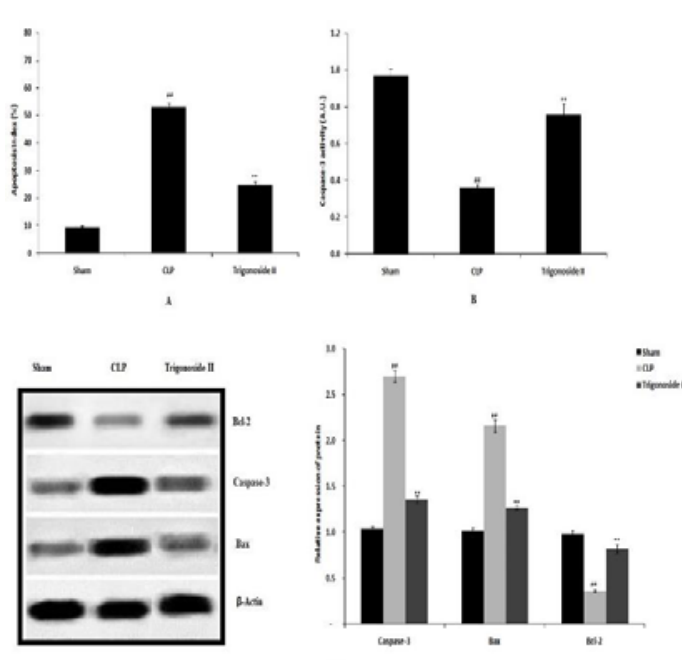

Figure 7: Effect of trigonoside II on myocardial cell apoptosis. (A) Apoptosis as measured using TUNEL assay; (B): Activity of caspase-3; and (C): Relative expressions of caspase- 3 , bax and bcl-2 in rat myocardial tissues; \# $p<0.05$, compared with sham group; ${ }^{* *} p<0.05$, compared with CLP group

\section{DISCUSSION}

Sepsis, a serious medical condition characterized by dysregulated systemic inflammatory responses and immunosuppression, remains a major health challenge. It causes multiple organ dysfunctions, including injury to myocardial tissue. This study investigated the protective effect of trigonoside II against sepsis-induced myocardial injury in rats, and the mechanism involved. The activities of myocardial enzymes and hemodynamic functions are altered in sepsis-induced myocardial injury [11]. Sepsis damages myocardial tissues, thereby altering the activities of LDH and CK-MB, as well as hemodynamic functions [12]. In this study, trigonoside II treatment significantly reversed the effects of sepsis on rat hemodynamic functions, as well as its effects on the activities of LDH and CK-MB. These results suggest that trigonoside II may confer some protection on the myocardium, and they are in agreement with those of previous studies $[11,12]$.

Sepsis-induced myocardial injury is characterized by neutrophil infiltration which triggers inflammatory response and edema [13]. The protein expressions of toll-like receptor 4 (TLR-4) and nuclear factor kappa-light-chain- enhancer of activated B cells (NF-kB) have been shown to be upregulated in myocardial tissues of myocardial injury rats [14]. The results of this study suggest that inflammation in myocardial injury rats may have been due to increased release of inflammatory cytokines. It is likely that the ameliorative effect of trigonoside II on sepsisinduced inflammation may occur via the TLR4/NF-kB pathway. Inflammatory mediators which activate MPO and promote oxidative stress, will always cause injury to organs including myocardial tissues [15]. Oxidative stress reduction decreases/prevents myocardial injury [16]. In this study, treatment of myocardial injury rats with trigonoside II significantly reduced sepsis-induced oxidative stress.

Sepsis-induced myocardial injury triggers apoptosis in myocardiocytes via the mitochondrial pathway [17]. Apoptotic markers such as bax, bcl-2 and caspase- 3 are central to mitochondrial function and any alteration in their expression levels will always result in apoptosis. It has been reported that proper expression of these proteins regulated mitochondrial function and reduced cell apoptosis [18]. The results of this study suggest that trigonoside II slows down myocardial cell apoptosis via regulation of bax, bcl-2 and caspase-3 protein expressions.

\section{CONCLUSION}

The results of this study indicate that trigonoside II confers protection against sepsis-induced myocardial injury via reduction in oxidative stress and regulation of the TLR-4/NF-kB inflammatory pathway. Thus, this compound can potentially be used for the clinical management cardiac damage.

\section{DECLARATIONS}

\section{Acknowledgement}

The authors of the manuscript are thankful to Heilongjiang University of Chinese Medicine, China for providing the facilities to conduct this work.

\section{Conflict of interest}

No conflict of interest is associated with this work.

\section{Contribution of authors}

We declare that this work was done by the authors named in this article and all liabilities pertaining to claims relating to the content of this 
article will be borne by the authors. FengRu Wang performed the study and contributes in the writing of manuscript. Lili Wu contributes in the statistical analysis and western blot assay. Qun Liang was designed the protocol, supervise the study and writes the manuscript.

\section{Open Access}

This is an Open Access article that uses a funding model which does not charge readers or their institutions for access and distributed under the terms of the Creative Commons Attribution License (http://creativecommons.org/licenses/by/ 4.0) and the Budapest Open Access Initiative (http://www.budapestopenaccessinitiative.org/rea d), which permit unrestricted use, distribution, and reproduction in any medium, provided the original work is properly credited.

\section{REFERENCES}

1. Gyawali B, Ramakrishna K, Dhamoon AS. Sepsis: The evolution in definition, pathophysiology, and management. SAGE Open Med 2019; 7: 2050312119835043.

2. Schulte W, Bernhagen J, Bucala R. Cytokines in sepsis: potent immunoregulators and potential therapeutic targets--an updated view. Mediators Inflamm 2013; 2013: 165974

3. Tsolaki V, Makris D, Mantzarlis K, Zakynthinos E. SepsisInduced Cardiomyopathy: Oxidative Implications in the Initiation and Resolution of the Damage. Oxid Med Cell Longev 2017; 2017: 7393525.

4. Uttara $B$, Singh AV, Zamboni $P$, Mahajan RT. Oxidative stress and neurodegenerative diseases: a review of upstream and downstream antioxidant therapeutic options. Curr Neuropharmacol 2009; 7(1): 65-74.

5. Shan H, Li T, Zhang L, Yang R, Li Y, Zhang M, Dong Y, Zhou Y, Xu C, Yang B, Liang H, Gao X, Shan H. Heme oxygenase-1 prevents heart against myocardial infarction by attenuating ischemic injury-induced cardiomyocytes senescence. E Bio Med 2019; 39: 5968.

6. Zhou S, Sun W, Zhang Z, Zheng Y. The role of Nrf2mediated pathway in cardiac remodeling and heart failure. Oxid Med Cell Longev 2014; 2014: 260429.

7. Jing L, Zhong-zhen Z, Hu-biao C, Review of Astragali Radix. Chinese Herbal Medicines 2011; 3(2): 90-105.
8. Xiao, HB, Krucker M, Albert K, Liang XM. Determination and identification of isoflavonoids in Radix astragali by matrix solid-phase dispersion extraction and highperformance liquid chromatography with photodiode array and mass spectrometric detection. J Chromatogr A4-2-2004; 1032(1-2): 117-124.

9. Graziani $V$, Scognamiglio $M$, Belli $V$, Esposito $A$, D'Abrosca B, Chambery A, Russo R, Panella $M$, Russo $A$, Ciardiello $F$, Troiani $T$, Potenza $N$, Fiorentino $A$. Metabolomic approach for a rapid identification of natural products with cytotoxic activity against human colorectal cancer cells. Sci Rep. 2018; 8(1): 5309.

10. Guide for the Care and Use of Laboratory Animals: Eighth Edition Committee for the Update of the Guide for the Care and Use of Laboratory Animals; National Research Council. 2010; ISBN: 0-309-15401-4.

11. Wang Z, Bu L, Yang $P$, Feng $S$, Xu F. Alleviation of sepsis-induced cardiac dysfunction by overexpression of Sestrin2 is associated with inhibition of $p$-S6K and activation of the p-AMPK pathway. Mol Med Rep. 2019; 20(3): 2511-2518.

12. Lim KH, Ko D, Kim JH. Cardioprotective potential of Korean Red Ginseng extract on isoproterenol-induced cardiac injury in rats. J Ginseng Res. 2013; 37(3): 273282.

13. Chen L, Deng $H$, Cui $H$, Fang J, Zuo Z, Deng J, Li Y, Wang $X$, Zhao $L$. Inflammatory responses and inflammation-associated diseases in organs. Oncotarget. 2017 Dec 14;9(6):7204-7218.

14. Wang $Y$, Hu $H$, Yin J, Shi $Y$, Tan J, Zheng L, Wang $C$, Xiaolu L, Xue M, Liu J, Wang Y, Li Y, Li X, Liu F, Liu Q, Yan S. TLR4 participates in sympathetic hyperactivity Post-MI in the PVN by regulating NF-KB pathway and ROS production. Redox Biol. 2019; 24: 101186.

15. Mittal M, Siddiqui MR, Tran K, Reddy SP, Malik AB. Reactive oxygen species in inflammation and tissue injury. Antioxid Redox Signal. 2014; 20(7): 1126-1167.

16. González-Montero J, Brito R, Gajardo Al, Rodrigo $R$. Myocardial reperfusion injury and oxidative stress: Therapeutic opportunities. World J Cardiol. 2018; 10(9): 74-86.

17. Yang F, Zhao LN, Sun Y, Chen Z. Levosimendan as a new force in the treatment of sepsis-induced cardiomyopathy: mechanism and clinical application. J Int Med Res. 2019; 47(5): 1817-1828.

18. Iliodromitis EK, Lazou A, Kremastinos DT. Ischemic preconditioning: protection against myocardial necrosis and apoptosis. Vasc Health Risk Manag. 2007; 3(5): 629-637. 